\title{
O papel do enfermeiro na orientação ao aleitamento de forma adequada:
}

\section{revisão bibliográfica}

\author{
The nurse's role in adequately guidling breastfeeding: a literature review \\ El papel de la enfermera en la orientación adecuada de la lactancia materna: revisión de la \\ literatura
}

Recebido: 01/11/2021 | Revisado: 09/11/2021 | Aceito: 16/11/2021 | Publicado: 18/11/2021

\author{
Dinalva de Almeida Santos \\ ORCID: https://orcid.org/0000-0002-8181-0835 \\ Universidade Ceuma, Brasil \\ E-mail: dinalvatesantos@hotmail.com \\ Cristina Limeira Leite \\ ORCID: https://orcid.org/0000-0002-7321-1496 \\ Universidade do Estado do Rio de Janeiro, Brasil \\ E-mail: crislimeira@gmail.com
}

\begin{abstract}
Resumo
O aleitamento materno consiste em uma das formas mais relevantes para benefício da saúde dos recém-nascidos, onde o leite proporciona benefícios não somente para o recém-nascido, mas também para a figura materna. Nesse sentido, quando ocorrem determinados fatores que são prejudiciais durante esse processo os cuidados precisam também ocorrer de forma ágil, podem ser destacados obstáculos ligados ao estresse materno, especialmente quando for a primeira gravidez da mãe. A nutriz deve receber uma ajuda profissional, procurar sempre que for oportunizada por informações, estar confiante e aberta física e emocionalmente. Nesse viés, o objetivo deste estudo, estar é analisar o papel do enfermeiro quanto a questão da orientação para promoção de aleitamento de forma adequada e sem ricos para mãe e para o bebê. Trata-se de uma revisão bibliográfica. A enfermagem se apresenta como de grande relevância na questão do apoio assistencial à mulher, dando início logo no pré-natal, parto e puerpério, em observância a sua rotina diária dentro do contexto sociocultural, particularmente quando essa mulher está lidando com sua primeira gravidez, as ações enfim, são fortalecidas em orientar, ensinar e prevenir para que não seja opção um desmame precoce.
\end{abstract}

Palavras-chave: Aleitamento; Papel do enfermeiro; Primíparas.

\begin{abstract}
Breastfeeding is one of the most relevant ways to benefit the health of newborns, where milk provides benefits not only for the newborn, but also for the mother figure. In this sense, when certain factors occur that are harmful during this process, care must also take place in an agile way, obstacles related to maternal stress can be highlighted, especially when it is the mother's first pregnancy. The nursing mother must receive professional help, seek whenever she is given the opportunity for information, be confident and open physically and emotionally. In this bias, the aim of this study is to analyze the role of nurses regarding the issue of guidance to promote breastfeeding adequately and without richness for mother and baby. This is a literature review.
\end{abstract}

Keywords: Breastfeeding; Nurse's role; Primarious.

\section{Resumen}

La lactancia materna es una de las formas más relacionadas con la salud de los recién nacidos, que no sólo es beneficiosa para los recién nacidos, sino también para las madres. En este sentido, los obstáculos relacionados con el estrés materno se destacan en el proceso cuando ciertos factores perjudiciales también requieren cuidados flexibles, especialmente cuando la madre está embarazada por primera vez. La nutrición debe recibir ayuda profesional, buscar ayuda cuando la información lo permita, y ser segura y abierta física y emocionalmente. En esta aldea, el objetivo de este estudio fue analizar el papel de los enfermeros en la promoción correcta de la orientación de la lactancia materna, sin padres ni bebés ricos. Esta es una revisión de la literatura. La atención es importante para ayudar a la mujer, en consonancia con su vida cotidiana en un contexto sociocultural desde el nacimiento, el parto y el parto temprano, en particular cuando la mujer se ocupa de su primer embarazo, y esas medidas se refuerzan en última instancia para determinar la dirección, Enseñar y prevenir el destete temprano se convierte en una opción. Palabras clave: Lactancia; Papel de la enfermera; Primario. 


\section{Introdução}

A saúde da mulher está propriamente relacionada a diversas alterações diárias que sucedem por alguma razão, dentre ele está o processo que sobrepuja o aleitamento materno. $\mathrm{O}$ alactamento é um fenômeno labiríntico que pode levar a mudanças hormonais e os mecanismos de adequações; caso não ocorram estas alterações de maneira correta apresentam potencialidade para gerar doenças ou circunstâncias exclusivas para as mulheres e podem ter consequências ao logo da vida (Mesquita et al., 2016).

Infelizmente a exiguidade de informação das mães no que diz respeito ao aleitamento materno, precipuamente as primíparas, tem sido visto como uma ameaça para o desmame prematuro (Magri et al., 2011).

A prática de amamentar deve ser compreendia em sua totalidade, afastando-se da ideologia da simples oferta de nutrientes da mãe para o filho, ou seja, a amamentação engloba a seguridade do desenvolvimento saudável de uma criança tanto no aspecto físico como mental, através do fortalecimento do vínculo materno infantil (Parenti et al., 2018).

Segundo a OMS juntamente com o Ministério da Saúde orientam de forma adequada o aleitamento materno exclusivo até os seis meses de vida do bebê e que somente assim sejam ofertados e complementados outros alimentos até os respectivos dois anos da criança ou ate mais (Brasil, 2015).

Por conseguinte, a maneira mais adequada de ofertar o alimento para um satisfatório desenvolvimento e crescimento de maneira saudável é sem duvidas por meio da amamentação, ainda sendo uma concepção verdadeira, é possível verificar o desenvolvimento e perpetuação de uma tendência promotora do desmame precoce e a adoção de aleitamento misto, culminando em um acentuado problema de saúde publica (Souza, 2010).

O profissional enfermeiro tem a responsabilidade de observar e interpretar toda a técnica do alactamento materno no âmbito social, cultural e familiar. Doravante desse entendimento, fornecer todos os cuidados a mãe, o filho e seus familiares. É necessário encontrar maneiras de se relacionar com as pessoas e fazê-las compreender a relevância da adoção de práticas saudáveis de aleitamento materno e explicar de forma cabal a importância do aleitamento materno exclusivo, exemplificando e evidenciando como funciona todo esse processo a fim de diminuir os ensejos do desmame precoce e fortalecer os cuidados a começar das necessidades exibidas pelas gestantes (Pimentel, da Silva \& Passos, 2015).

O enfermeiro precisa estar capacitado para ofertar uma assistência eficaz, benéfica total e contextualizada, sempre respeitando o sentimento e as histórias de vida de cada mulher e ajudá-la a superar, desvendar medos, adversidades e vulnerabilidades durante todo o processo do alactamento (Ferreira et al., 2016).

Nessa conjuntura, o objetivo deste trabalho é explorar o papel do enfermeiro na orientação ao aleitamento de forma adequada: revisão bibliográfica, a fim de estabelecer o incentivo ao aleitamento materno.

O artigo está disposto em sessões onde tratarão a introdução, a metodologia utilizada para a elaboração do artigo e os resultados e discussões como produto de todo o texto produzido, por fim as considerações finais, encerrando a ideia central e reafirmando os pontos de maior relevância encontrados ao longo desta produção.

\section{Metodologia}

Foi realizada uma pesquisa de revisão integrativa de literatura, para descrever e identificar o papel do enfermeiro na orientação ao aleitamento de forma adequada: revisão bibliográfica.

Segundo Souza, Silva e Carvalho (2010), uma revisão abrangente da literatura é um método de revisão que permite a compreensão e análise de pesquisas não experimentais e experimentais, de forma que pesquisas relevantes na prática do conhecimento possam ser resumidas por meio dos resultados a seguir. 
Mendes, Silveira e Galvão (2008) explicam que o processo de elaboração é dividido em seis etapas: elaboração das questões norteadoras busca ou amostragem na literatura, coleta de dados, análise crítica dos estudos incluídos, discussão dos resultados e revisão das apresentações abrangentes.

Trata-se de uma revisão bibliográfica do tipo integrativa, com coleta de dados realizados a partir de fontes secundárias, por meio de levantamento bibliográfico, tendo características descritivas, retrospectiva, com abordagem qualitativa, através de seleção criteriosa de artigos, a partir dos seguintes descritores: Aleitamento + Papel do enfermeiro + Primíparas. Com busca realizadas nas bases de dados: Scielo, Lilacs, Pubmed entre outros.

Para as busca, foram utilizados artigos publicados no Brasil, no periodo de 2009 a 2021, e que tenham os descritores ja citados acima. Nesse momento, os critérios de inclusão que foram utilizados para selecionar os artigos foram: artigos publicados em português, que tenha relacão direta com a temática abordada. Os critérios de exclusão foram artigos que não estão dentro do período selecionado nesse estudo e que não tenha as palavras-chaves que foram selecionadas para filtragem da pesquisa.

A presente construção, quanto a sua metodologia, consiste numa revisão bibliográfica, fazendo uso de pesquisa descritiva, com suporte de periódicos das seguintes base de dados: LILACS - Literatura Latino-Americana em Ciências de Saúde, SCIELO - Scientific Electronic Library e BIREME - Biblioteca Regional de Medicina, dos últimos 11 anos. Através do exclarecimento dos objetivos citados, tal pesquisa apresenta como beneficio principal, contribuir com esclarecimentos sobre o pré-natal para gestantes que ainda não tem experiência com a gestação.

Além disso, os dados obtidos foram tabulados com o auxílio de programas de texto, e organizads em tabelas e quadros para uma melhor visualização e análise dos resultados. Sendo assim, foi possível conhecer mais profundamente o papel do enfermeiro na orientação ao aleitamento de forma adequada.

O prisma mostra os estudos selecionados que fizeram parte da construção do trabalho, logo em seguida houve a elaboração do quadro contendo ano de publicação, periódico, autores e título. 
Figura 1: Fluxograma de recuperação dos artigos.

\section{TOTAL DE ESTUDOS IDENTIFICADOS}

LILACS

BIREME

SCIELO

EXCLUSÃO DE DUPLICADOS (18)

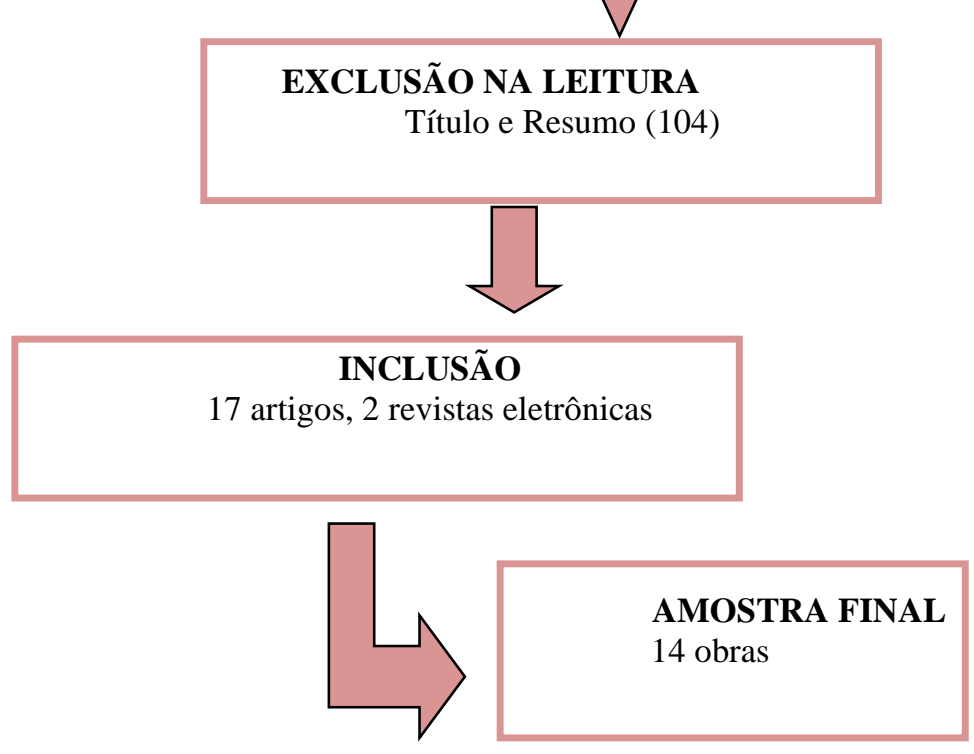

Fonte: Autores (2021)

A amostra desse estudo, depois dos critérios aplicados, se resume numa análise de 14 (quatorze) periódicos. O quadro 1 mostra cada um desses periódicos e suas especificações, como: ano; periódico; nome dos autores e título.

\section{Resultados e Discussões}

Com base nos artigos científicos foram eleitos 14 e lidos na integra onde se encontram arroladas: Informações sobre ano, periódico, os autores, título do artigo e a conclusão (Quadro 1). 
Quadro 1. Distribuição dos estudos conforme ano, periódico, autor, titulo e conclusão. Imperatriz, 2021.

\begin{tabular}{|c|c|c|c|c|}
\hline ANO & PERIÓDICO & AUTORES & TÍTULO & CONCLUSÃO \\
\hline 2009 & $\begin{array}{l}\text { Ministério da } \\
\text { Saúde }\end{array}$ & BRASIL & $\begin{array}{l}\text { Saúde da criança: nutrição } \\
\text { infantil: aleitamento materno e } \\
\text { alimentação complementar. }\end{array}$ & $\begin{array}{c}\text { A IMA é um comportamento construído ao } \\
\text { longo da vida e antecede a prática da } \\
\text { amamentação. }\end{array}$ \\
\hline 2016 & $\begin{array}{l}\text { Revista } \\
\text { Conexão } \\
\text { Eletrônica }\end{array}$ & FERREIRA, G. R. et al. & $\begin{array}{l}\text { O papel da enfermagem na } \\
\text { orientação do aleitamento } \\
\text { materno exclusivo. }\end{array}$ & $\begin{array}{l}\text { O papel da Enfermagem fica evidenciado } \\
\text { na necessidade de ser realizada de forma } \\
\text { concisa e coerente, prestando uma } \\
\text { assistência de qualidade e humanizada às } \\
\text { futuras mães. }\end{array}$ \\
\hline 2009 & $\begin{array}{l}\text { Perspectivas } \\
\text { Online }\end{array}$ & $\begin{array}{l}\text { AMORIM, M. M.; DE } \\
\text { ANDRADE, E. R. }\end{array}$ & $\begin{array}{l}\text { Atuação do enfermeiro no PSF } \\
\text { sobre aleitamento materno. }\end{array}$ & $\begin{array}{l}\text { Este estudo permitiu conhecer a } \\
\text { importância do profissional enfermeiro } \\
\text { dentro do PSF atuando e orientando as } \\
\text { gestantes quanto à prática do aleitamento } \\
\text { materno que é de total relevância para os } \\
\text { lactentes. }\end{array}$ \\
\hline 2009 & $\begin{array}{l}\text { Universitas: } \\
\text { Ciências da } \\
\text { Saúde. }\end{array}$ & BULLON, R. B. et al. & $\begin{array}{l}\text { A influência da família e o papel } \\
\text { do enfermeiro na promoção do } \\
\text { aleitamento materno. }\end{array}$ & $\begin{array}{l}\text { Para que o aleitamento materno seja uma } \\
\text { prática consolidada, é necessária a atuação } \\
\text { contínua do Estado, Instituições e } \\
\text { profissionais de saúde, comunidade e } \\
\text { família, em especial o pai e as avós. }\end{array}$ \\
\hline 2011 & E-scientia. & $\begin{array}{l}\text { DE CARVALHO, J. K. } \\
\text { M.; CARVALHO, C. G.; } \\
\text { MAGALHÃES, S. R. }\end{array}$ & $\begin{array}{l}\text { A importância da assistência de } \\
\text { enfermagem no aleitamento } \\
\text { materno. }\end{array}$ & $\begin{array}{c}\text { Este trabalho contribuirá para que haja } \\
\text { mais informações acerca da atuação da } \\
\text { enfermagem no que tange a amamentação e } \\
\text { dessa forma proporcionar para } \\
\text { profissionais de saúde, pacientes e } \\
\text { familiares maiores conhecimentos e } \\
\text { segurança frente à questão da } \\
\text { amamentação. }\end{array}$ \\
\hline 2013 & $\begin{array}{l}\text { Saúde em } \\
\text { debate }\end{array}$ & $\begin{array}{l}\text { BATISTA, K. R. de A.; } \\
\text { FARIAS, M. do C. A. D.; } \\
\text { MELO, W. dos S. N. }\end{array}$ & $\begin{array}{l}\text { Influência da assistência de } \\
\text { enfermagem na prática da } \\
\text { amamentação no puerpério } \\
\text { imediato. }\end{array}$ & $\begin{array}{l}\text { Almejamos que haja assistência de } \\
\text { enfermagem no puerpério imediato com } \\
\text { ações comunitárias de promoção à saúde, a } \\
\text { fim atingir o recomendado pelo Ministério } \\
\text { da Saúde, acerca da amamentação. }\end{array}$ \\
\hline 2013 & $\begin{array}{c}\text { Revista } \\
\text { Brasileira de } \\
\text { Enfermagem, }\end{array}$ & SILVA, E. P. et al. & $\begin{array}{l}\text { Diagnósticos de enfermagem } \\
\text { relacionados à amamentação em } \\
\text { unidade de alojamento conjunto. }\end{array}$ & $\begin{array}{l}\text { Estima-se que os diagnósticos de } \\
\text { enfermagem relacionados à Amamentação } \\
\text { contribuirão para que os cuidados de } \\
\text { enfermagem possam ser mais direcionados, } \\
\text { de modo a promover uma assistência mais } \\
\text { qualificada, humanizada e eficaz. }\end{array}$ \\
\hline 2013 & $\begin{array}{l}\text { Ciência, } \\
\text { Cuidado e } \\
\text { Saúde. }\end{array}$ & D'ARTIBALE, E. F. et al. & $\begin{array}{l}\text { Atuação do acadêmico de } \\
\text { enfermagem no banco de leite } \\
\text { humano: relato de } \\
\text { experiência/Performance of the } \\
\text { nursing undergraduate in a human } \\
\text { milk bank: an experience report. }\end{array}$ & $\begin{array}{l}\text { Assim, se formam e consolidam relações } \\
\text { e conhecimentos necessários para uma } \\
\text { formação profissional Adequada, } \\
\text { propiciando o desenvolvimento de } \\
\text { pensamentos críticos, reflexivos e } \\
\text { criativos, que são consequências dessa } \\
\text { prática profissional enriquecedora. }\end{array}$ \\
\hline 2016 & $\begin{array}{l}\text { Revista } \\
\text { Conexão } \\
\text { Eletrônica. }\end{array}$ & FERREIRA, G. R. et al. & $\begin{array}{l}\text { O papel da enfermagem na } \\
\text { orientação do aleitamento } \\
\text { materno exclusivo. }\end{array}$ & $\begin{array}{l}\text { O papel da Enfermagem fica evidenciado } \\
\text { na necessidade de ser realizada de forma } \\
\text { concisa e coerente, prestando uma } \\
\text { assistência de qualidade e humanizada às } \\
\text { futuras mães. }\end{array}$ \\
\hline 2020 & $\begin{array}{l}\text { Research, } \\
\text { Society and } \\
\text { Development. }\end{array}$ & MUCHA, A. M. et al. & $\begin{array}{l}\text { Orientação da amamentação na } \\
\text { alta hospitalar: uma revisão } \\
\text { integrativa. }\end{array}$ & $\begin{array}{c}\text { É importante a participação da enfermagem } \\
\text { no parto e na alta hospitalar oferecendo } \\
\text { o Apoio necessário para a puérpera com } \\
\text { empatia e serviços qualificados, } \\
\text { minimizando, desta Forma, o desmame } \\
\text { precoce. }\end{array}$ \\
\hline
\end{tabular}




\begin{tabular}{|c|c|c|c|c|}
\hline 2010 & $\begin{array}{l}\text { La Santé de } \\
\text { l'homme. }\end{array}$ & $\begin{array}{c}\text { SOUZA, C. B.; } \\
\text { ESPÍRITO SANTO, L. } \\
\text { C.; GIUGLIANI, E. R. J. }\end{array}$ & $\begin{array}{l}\text { Políticas públicas de incentivo ao } \\
\text { aleitamento materno: a } \\
\text { experiência do Brasil. }\end{array}$ & $\begin{array}{l}\text { Compreende-se que a mulher precisa ser } \\
\text { orientada por um profissional de saúde para } \\
\text { que esse processo seja mais tranquilo, } \\
\text { tendo sempre o seu direito de decidir } \\
\text { preservado. }\end{array}$ \\
\hline 2017 & $\begin{array}{l}\text { Rev. } \\
\text { Enfermagem } \\
\text { Revista. }\end{array}$ & $\begin{array}{l}\text { OLIVEIRA, C.a M. de, et } \\
\text { al. }\end{array}$ & $\begin{array}{c}\text { Promoção do Aleitamento } \\
\text { Materno: intervenção educativa } \\
\text { no âmbito da Estratégia de Saúde } \\
\text { da Família. }\end{array}$ & $\begin{array}{l}\text { Verificou-se a importância da promoção de } \\
\text { ações educativas em saúde em grupos de } \\
\text { gestantes, o que possibilitou esclarecer } \\
\text { dúvidas e fornecer subsídios para a } \\
\text { aquisição de conhecimentos sobre o } \\
\text { aleitamento materno exclusivo. }\end{array}$ \\
\hline 2018 & Inova Saúde. & CRISTIANO, D. P. et al. & $\begin{array}{l}\text { Prevenção de maloclusão: } \\
\text { conhecimento de mães de } \\
\text { crianças com } 3 \text { e } 4 \text { anos. }\end{array}$ & $\begin{array}{l}\text { conclui-se que a falta de tempo, cuidados } \\
\text { com as mamas, conhecimento e fatores } \\
\text { culturais fazem as mulheres pararem de } \\
\text { amamentar precocemente, implicando no } \\
\text { surgimento de novos hábitos que façam as } \\
\text { crianças parem de chorar, como o uso do } \\
\text { bico, e, se alimentem com facilidade, como } \\
\text { o uso da mamadeira, os quais com o tempo } \\
\text { se tornam deletérios, aumentando o risco } \\
\text { de terem maloclusão }\end{array}$ \\
\hline 2016 & $\begin{array}{l}\text { Rev Gaúcha } \\
\text { Enferm. }\end{array}$ & $\begin{array}{l}\text { QUEIROZ, M. V. O. et } \\
\text { al. }\end{array}$ & $\begin{array}{l}\text { Grupo de gestantes adolescentes: } \\
\text { contribuições para o cuidado no } \\
\text { pré-natal. }\end{array}$ & $\begin{array}{c}\text { As considerações e as sugestões das } \\
\text { adolescentes contribuíram para nortear o } \\
\text { enfermeiro no desenvolvimento do grupo e } \\
\text { efetivá-lo como espaço estratégico de } \\
\text { cuidados e apoio às adolescentes grávidas } \\
\text { na atenção básica. }\end{array}$ \\
\hline
\end{tabular}

Fonte: Autores (2021).

Amorim e De Andrade (2009) salientaram a importância do profissional enfermeiro que está em contato direto com as gestantes e puérperas esteja apto para acolher as mães e orientar sobre os benefícios da amamentação não apenas para mesma como para os filhos, famílias e sociedade. O mesmo deve organizar palestras, encontros e atividades diárias de apoio e promoção do aleitamento materno. A pesquisa dos autores também expos a relevância para a construção de grupos de educação em saúde, que permite ao enfermeiro transmitir conhecimentos e esclarecer duvidas e questões de acordo com suas demandas. Em síntese, os autores enfatizam o papel do enfermeiro como o responsável pela execução na tomada de decisões e aplicação de conhecimentos, auxiliando as mães na amamentação adequada, melhorando a saúde de seus filhos.

Foi evidenciado o papel fundamental da família durante o processo do aleitamento materno de forma adequada, concentrando nos papeis do companheiro e da mãe da mulher. Os atores acreditam que, alem de estimular a formação de vínculos afetivos entre mãe e o seu filho, a amamentação é a maneira mais plausível para refrear a morbimortalidade infantil, trazendo vantagens para ambas as partes. Concisamente os autores concluem que é inescusável fortalecer o processo de amamentação através de estímulo do estado, da família e precipuamente do enfermeiro (Bullon et al, 2010).

De Carvalho, Carvalho e Magalhães (2011) enfatizou o valor que aleitamento materno possui, pois ele é uma fonte de nutrição e componentes imunológicos e psicológicos para promover o desenvolvimento congruente do bebê. Além disso, eles também veem os aspectos históricos, culturais e sociais do alactamento materno que é um fator importante na decisão da lactante de amamentar. O profissional enfermeiro é quem possui o contato direto com a puérpera desde a gravidez até o puerpério, por isso a necessidade e o interesse do mesmo em participar de programas de educação em saúde e orientar antes e depois do parto para assim obter uma amamentação adequada.

Batista, Farias \& Melo (2013) observou durante um estudo com 16 mulheres que já vivenciaram a amamentação e pontuaram a não contribuição do enfermeiro de modo que as mulheres não conseguiram evitar o desmame precoce, principalmente evidenciado pelo o não conhecimento da importância do aleitamento. Os autores denotam a relevância da 
assistência prestada a domicilio objetivando uma formação de vinculo de modo que a parturiente sinta-se segura e acolhida lembrando a importância de um atendimento diferenciado de acordo com cada necessidade encontrada.

Silva et al. (2013) apontaram os diagnósticos de enfermagem em um agrupado de alojamento com 83 crianças, expondo que cerca de $78 \%$ dos bebês obtinham uma amamentação ineficiente. Durante a conclusão os autores denotam a importância do diagnostico de enfermagem referente à amamentação para que o profissional enfermeiro possa dispor uma assistência humanizada, alcunhada e efetiva.

Dando seguimento aos diagnósticos de enfermagem que o profissional enfermeiro irá elaborar as suas metas e propósitos, traçando um plano de cuidados que estará alusivo a todas as problemáticas, de forma particularizada, com dimensões fundamentais para que não haja interferência no alactamento materno, reduzindo assim o desmame prematuro (d'artibale et al., 2013).

Ferreira et al. (2016) alegaram a relevância do alactamento materno exclusivo até os seis meses de vida do bebê transferindo imunidades também para a lactante, este estimulo devera ser executado pelo o enfermeiro onde o mesmo devera possuir um contato direto com a própria. Os autores explicitaram o papel do enfermeiro de maneira coesa e precipuamente humanizado com as puérperas desde parto até o pós-parto, bem como a execução do enfermeiro no cuidados com os as mamas, orientando de forma integral o posicionamento exato para amamentar, e precaução de patologias que possam vir a cometer as puérperas. Essa providencia contribuem para tornar a restauração das mães o mais saudável e plácido.

Mucha et al. (2020) durante uma pesquisa literária repararam que mesmo no dias atuais ainda há problemas durante a orientação do profissional enfermeiro para as puérperas. Os autores salientam a importância da cooperação do enfermeiro no decorrer do parto até o presente da alta hospitalar e que a acessão dos serviços de enfermagem apropriada e de empatia por parte do enfermeiro reduza o desmame prematuro.

É de suma importância destacar que para o alactamento materno tenha êxito é fundamental que primeiramente a mãe manifeste o desejo para amamentar (Bullon et al., 2010). Conquanto por mais que essa decisão pareça particular e privativa, várias razoes influencia nessa variável. A rede de apoio familiar, precipuamente do companheiro e da mãe é crucial no incentivo ao aleitamento. Alem de tudo o acesso a programas e estruturas de saúde governamentais e a informação (Bullon et al., 2010).

O sistema Único de Saúde (SUS) promovem programas governamentais centralizados para que haja um acesso global por meio da população baseado nas políticas do aleitamento materno. Além disto, durante as ultimas décadas têm se notado o acrescimento dos números do alactamento materno de forma exclusiva até os seis meses e se encontra relacionados morbimortalidade infantil (Bullon et al., 2010; Souza., Espírito Santo \& Giugliani 2010).

Para que uma mãe possa utilizar a rede de apoio à amamentação, é inescusável que as pessoas que acercam possuam entendimento acerca do aleitamento materno. Portanto, os profissionais enfermeiros atuam compartilhando conceitos sobre nutrição do leite materno (discutidos no primeiro tópico deste estudo) e técnicas que auxiliam as mães a propiciar uma amamentação agradável e adequada (Ferreira et al., 2016).

A conduta do profissional enfermeiro deverá iniciar já no pré - natal e acompanhar durante a gestação até o pós-parto. O incentivo ao aleitamento materno devera ser realizado de forma agradável e gradual, sempre portando as duvidas e temores que a mãe possa externar. E desmistificar as concepções errôneas que a mãe venha a ter e a dedicação particular do enfermeiro com cada puérpera pode ser definitiva para um aleitamento apropriado (Brasil, 2009; Ferreira et al., 2016).

$\mathrm{O}$ enfermeiro alem de ofertar o seu papel como intercessor e vetor de conhecimento, utiliza técnicas de enfermagem durante o processo da amamentação auxiliando as mães a continuar o tempo previsto do alactamento. Técnicas apropriadas como a pega correta da mama, o posicionamento da cabeça do lactente e quais os devidos cuidados que as mães devem ter com 
as mamas e os mamilos são irrefutáveis para um aleitamento sublime, precipuamente se forem questionadas durante as primeiras amamentações (Bullon et al., 2010; Ferreira et al., 2016).

É de suma importância que o enfermeiro tenha plena convicção do seu papel global durante a promoção do alactamento materno, desse modo ele intensifique sua evolução e se especialize na área que deseja atuar para prover uma atenção eficiente às puéperas e com isso se destacar em seu papel transformador na vida da população e comunidade do qual se encontra adentrado (Brasil, 2009; Bullon et al., 2010; Ferreira et al., 2016).

Figura 2 - Cuidados ao amamentar.

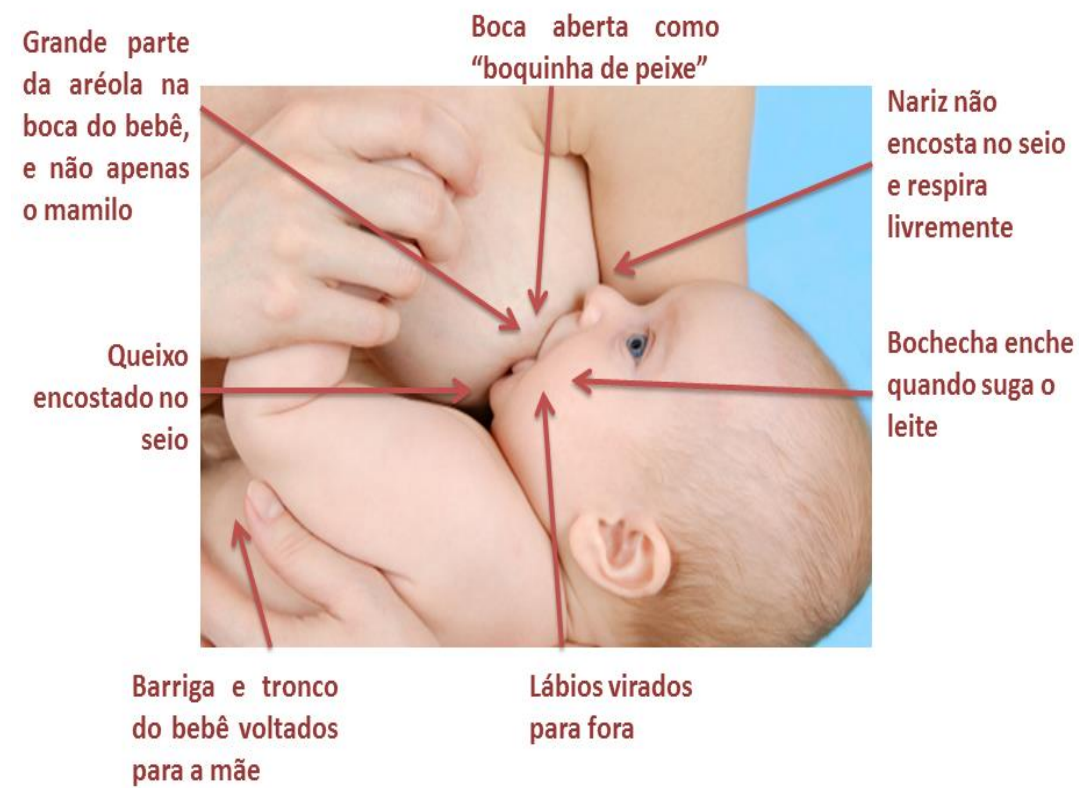

Fonte: Autores (2021).

Na maioria dos casos a mulher tende a apresentar fissuras mamárias em decorrência do aleitamento materno, algo que pode ajudar na prevenção e funciona de fato é buscar sempre uma orientação profissional do enfermeitro no que concerne aos cuidados com a mama, ou seja, os profissionais devem ajudar sobre como buscar manter as mamas sempre secas, mesmo depois de realizar o aleitamento, fornecer as primeiras mamadas no peito menos acometido, deixar por um bom período de tempo os seios expostos à luz solar, essa ação fortalece os tecidos areolar e mamilar (Oliveira, et al., 2017).

Caso a mulher se queixe de dores nas mamas, pode estar ligada a pega feita de maneira errada da mama devida seu posicionamento incorreto. A posição correta do bebê ajuda no ato de sucção e é indispensável para eliminar as chances de ocorrer lesões mamárias (Cristiano et al., 2018). 
Figura 3 - Papel do enfermeiro.

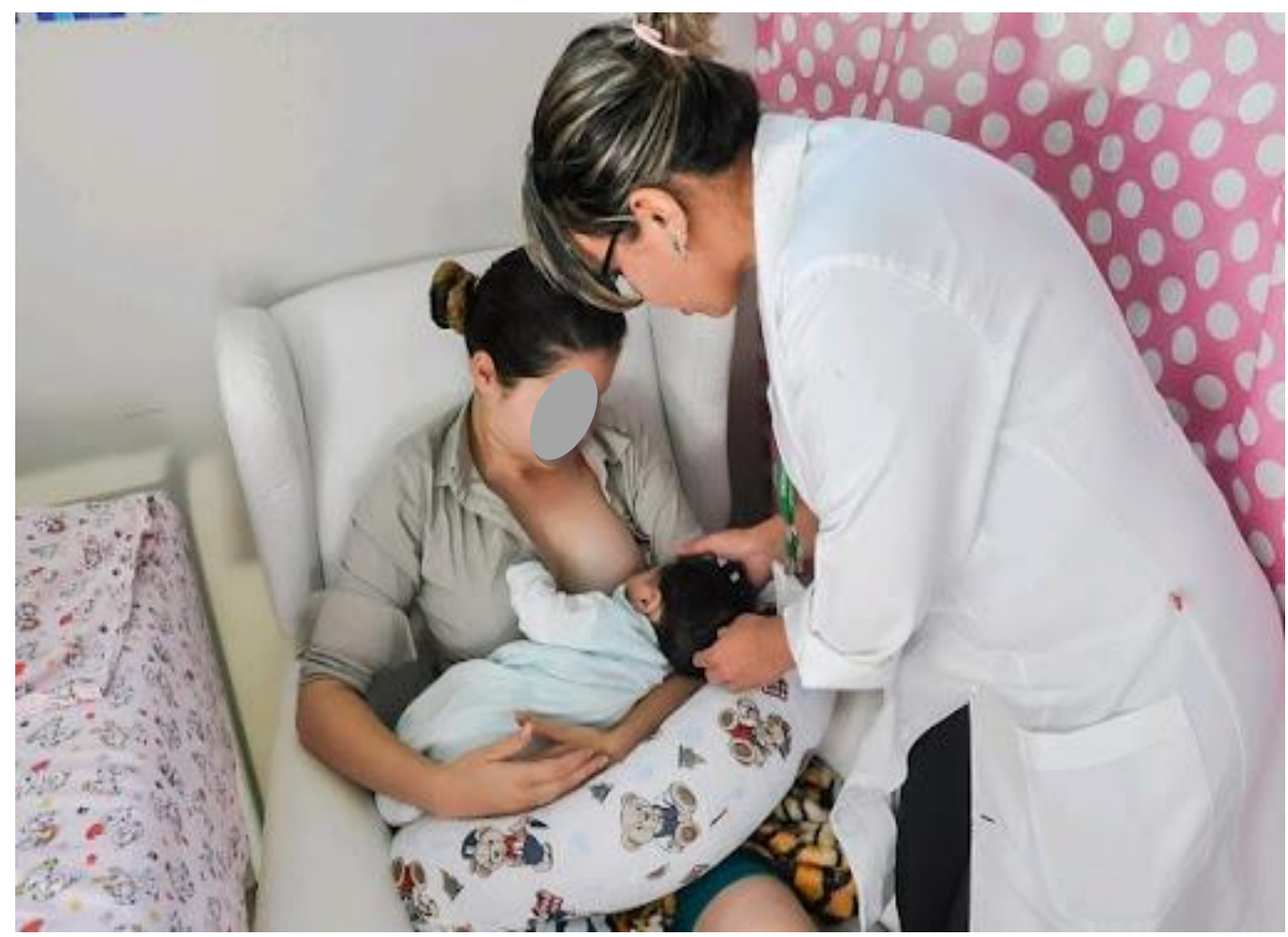

Fonte: Queiroz et al (2016).

O enfermeiro, nesse aspecto, é um profissional que está sempre buscando ajudar essas pessoas, pois ele não enxerga apenas a doença, mas possui um olhar humanizado, ajudando o puérpera e a família a enfrentar momentos e situações de dor e sofrimento diante do adoecimento.

\section{Considerações Finais}

Durante o desenvolvimento da literatura é unânime que o aleitamento materno é indispensável para que ocorra o desenvolvimento apropriado da criança. O alactamento é uma relação condicional entre a mãe e o lactente trazendo apanágios para ambas as partes. A mãe proporciona todos os alimentos nutritivos e necessários para o bebê e designa uma ligação psicológica com a própria durante o momento da amamentação, em compensação, o ato de amamentar facilita na recuperação do parto, normalização hormonal e nos problemas relativos ao aleitamento.

O profissional enfermeiro possui um papel imprescindível no aleitamento materno adequado na promoção da saúde da mulher e do lactente. Diante a criação de confiança com a parturiente desde do pré-natal até a alta hospitalar da puérpera, o enfermeiro ajuda a transmitir conhecimentos e técnicas para demitologizar preconceitos e incertezas a respeito da técnica de aleitamento e proporciona a mãe para que a mesma possa dispor um alimento eficaz para seu bebê filho de forma saudável e plácida.

Dessa forma, o presente estudo irá corroborar para futuras revisões retratando o papel do enfermeiro na orientação ao aleitamento de forma adequada: revisão bibliográfica podendo auxiliar na redução da morbimortalidade infantil e assistir de maneira adequada o desenvolvimento do bebê.

Em síntese, diante das pesquisas envolvidas, faz-se necessário encontrar e estabelecer novas pesquisas, abordando principalmente o papel do enfermeiro na orientação ao aleitamento de forma adequada: revisão bibliográfica. Portanto, 
pesquisas futuras podem trazer contribuições benéficas para as evidências científicas, revelar inovações e cuidados atuais, e ter como objetivo contribuir com a literatura científica e expandir novos conhecimentos.

\section{Referências}

Amorim, M. M., \& de Andrade, E. R. (2009). Atuação do enfermeiro no PSF sobre aleitamento materno. Perspectivas Online 20072011, 3(9).https://repositorio.ufmg.br/handle/1843/BUOS-9CYECM.

Batista, K. R. D. A., Farias, M. D. C. A. D. D., \& Melo, W. D. S. N. D. (2013). Influência da assistência de enfermagem na prática da amamentação no puerpério imediato. Saúde em debate, 37, 130-138. https://www.scielo.br/j/sdeb/a/XtmLcbYNXGxNNCsDFkwQXcq/abstract/?lang=pt.

BRASIL. (2009) Ministério da Saúde. Saúde da criança: nutrição infantil: aleitamento materno e alimentação complementar. Brasília: MS. https://bvsms.saude.gov.br/bvs/publicacoes/saude_crianca_aleitamento_materno_cab23.pdf10

Brasil. (2015). Saúde da criança: aleitamento materno e alimentação complementar. Ministério da Saúde. https://bvsms.saude.gov.br/bvs/publicacoes/saude_crianca_aleitamento_materno_cab23.pdf.

Bullon, R. B., Cardoso, F. A., Peixoto, H. M., \& de Miranda, L. F. (2009). A influência da família e o papel do enfermeiro na promoção do aleitamento materno. Universitas: Ciências da Saúde, 7(2), 49-70. https://www.gti.uniceub.br/cienciasaude/article/view/990.

Cristiano, D. P., Ferreira, M. R., Roque, A., Sônego, F. G. F., de Azevedo Simões, P. W. T., Soratto, J., ... \& Ferraz, F. (2018). Prevenção de maloclusão: conhecimento de mães de crianças com 3 E 4 ANOS. Inova Saúde. https://core.ac.uk/download/pdf/236395692.pdf>.

D'artibale, E. F., Machado, A. A., Dinardi, J. L., Genovez, C. B., Ichisato, S. M. T., \& Serafim, D. (2013). Atuação do acadêmico de enfermagem no banco de leite humano: relato de experiência/Performance of the nursing undergraduate in a human milk bank: an experience report. Ciência, Cuidado e Saúde, 12(3), 582-588. https://periodicos.uem.br/ojs/index.php/CiencCuidSaude/article/view/19230.

Carvalho, J. K. M., Carvalho, C. G., \& Magalhães, S. R. (2011). A importância da assistência de enfermagem no aleitamento materno. E-scientia, 4(2), 11-20. https://revistas.unibh.br/dcbas/article/view/186.

Ferreira, G. R., Lima, T. C. F., Coelho, N. M. D., Grilo, P. M. S., \& Gonçalves, R. Q. (2016). O papel da enfermagem na orientação do aleitamento materno exclusivo. Revista Conexão Eletrônica, 13(1), 1-18. http://www.aems.edu.br/conexao/edicaoanterior/Sumario/2016/downloads/1.\%20Ci\%C3\%AAncias\%20Biol\%C3\%B3gicas\%20e\%20Ci\%C3\%AAncias\%20da \%20Sa\%C3\%BAde/070_Inicia\%C3\%A7\%C3\%A3o\%20-\%20O\%20Papel\%20da\%20Enfermagem....pdf>.

Magri, M., Van Der Sand, I. C. P., Fernandes, C. R., da Silva, E. B., \& Leite, M. T. (2011). Conhecimento de primíparas, mães de lactentes residentes em Palmeira das Missões/Rio Grande do Sul sobre aleitamento materno. Journal of Nursing and Health, 1(2), 265-281. https://periodicos.ufpel.edu.br/ojs2/index.php/enfermagem/article/view/3440.

Mesquita, A. L., Souza, V. A. B., Santos, T. N. D., \& Santos, O. P. D. (2016). Atribuições de enfermeiros na orientação de lactantes acerca do aleitamento materno. Revista de Divulgação Científica Sena Aires, 5(2), 158-170. http://revistafacesa.senaaires.com.br/index.php/revisa/article/view/267.

Mucha, A. M., Lohmann, P. M., Laste, G., \& Marchese, C. (2020). Orientação da amamentação na alta hospitalar: uma revisão integrativa. Research, Society and Development, 9(7), e219974119-e219974119. https://www.rsdjournal.org/index.php/rsd/article/view/4119>.

Oliveira, C. M., Santos, T. C., Melo, I. M., Aguiar, D. T., \& Netto, J. J. M. (2017). Promoção do Aleitamento Materno: intervenção educativa no âmbito da Estratégia de Saúde da Família. Enfermagem revista, 20(2), 99-108. < https://www.researchgate.net/profile/Jose-MouraoNetto/publication/322292609_Promocao_do_Aleitamento_Materno_intervencao_educativa_no_ambito_da_Estrategia_de_Saude_da_Familia_Promotion_of_ breastfeeding_educational_intervention_in_the_context_of_the_Family_Health_Strategy/links/5a50f59faca2725638c57d39/Promocao-do-Aleitamento-

Materno-intervencao-educativa-no-ambito-da-Estrategia-de-Saude-da-Familia-Promotion-of-breastfeeding-educational-intervention-in-the-context-of-the-

Family-Health-Strategy.pdf.

Parenti, P. W., da Silva, L. C. F. P., Sola, E. P. S., Venâncio, K. C. P. M., Ferreira, F. M., \& de Camargo, J. D. C. S. Experiências de enfermeiras da atenção primária à saúde no atendimento pré-natal de adolescentes Experiences of primary health care nurses in the prenatal care of adolescents Experiencias de enfermeras de la atención primaria a la salud en el atendimiento pre-natal de adolescentes. http://seer.uftm.edu.br/revistaeletronica/index.php/refacs/article/view/2796>..

Pimentel, A. K. S.; da silva, O. D. C.; \& Passos, L. O papel do enfermeiro na orientação sobre aleitamento materno para as prímiparas: uma revisão de literatura. Editora Realize. 2015. https://editorarealize.com.br/editora/anais/conbracis/2016/TRABALHO_EV055_MD4_SA4_ID66_31052016134213.pdf.

Queiroz, M. V. O., Menezes, G. M. D., Silva, T. J. P., Brasil, E. G. M., \& Silva, R. M. D. (2017). Grupo de gestantes adolescentes: contribuições para o cuidado no pré-natal. Revista Gaúcha de Enfermagem, 37. https://www.scielo.br/j/rgenf/a/nVwSzngmhqPDNFQJQz9fmgj/?lang=pt\&format=html>.

Silva, E. P. D., Alves, A. R., Macedo, A. R. M., Bezerra, R. M. D. S. B., Almeida, P. C. D., \& Chaves, E. M. C. (2013). Diagnósticos de enfermagem relacionados à amamentação em unidade de alojamento conjunto. Revista Brasileira de Enfermagem, 66, 190-195. https://www.scielo.br/j/reben/a/Tgkx3KC55yBgrVHXXK9J4BB/abstract/?lang=pt.

Souza, C. B., Espírito Santo, L. C., \& Giugliani, E. R. J. (2010). Políticas públicas de incentivo ao aleitamento materno: a experiência do Brasil. La Santé de l'homme, 48. https://attena.ufpe.br/handle/123456789/18037.

Souza, E. A. C. S. (2010). Reflexões acerca da amamentação: uma revisão bibliográfica. https://repositorio.ufmg.br/handle/1843/BUOS-9CYECM. 